\title{
PRESENTACIÓN AL MONOGRÁFICO: CARTAS Y OTROS TESTIMONIOS PARA LA EDUCACIÓN (SOCIAL) Y LA COMUNICACIÓN
}

\author{
PRESENTATION TO THE MONOGRAPH: LETTERS AND OTHER \\ TESTIMONIES FOR (SOCIAL) EDUCATION AND COMMUNICATION
}

\author{
Ercilia Maria Angeli Teixeira de Paula \\ Coordinadora del monográfico \\ Universidade Estadual de Maringá, Brasil \\ https://orcid.org/0000-0002-8619-7558 \\ erciliaangeli@yahoo.com.br
}

Cómo citar este artículo: Paula, E. M. A. T. (2020). Presentación al monográfico: Cartas y otros testimonios para la educación (social) y la comunicación. Hachetetepé. Revista científica en Educación y Comunicación, (20), 3-5.doi: http://doi.org/10.25267/Hachetetepe.2020.i20.2

Queridos lectores y lectoras de la Revista Hachetetepé:

En este número titulado "Cartas y otros testimonios para la educación (social) y la comunicación" trataremos un poco de la realidad brasileña, de América latina y Portugal, en relación con las diferentes formas de comunicación, de entre ellas, las cartas que andan olvidadas en las escuelas y por el conjunto de la sociedad. De esta manera, iniciaremos la presentación de este monográfico con una carta/introducción sobre las delicias y los desafío de escribir cartas en la contemporaneidad.

Estamos en febrero en Brasil. Es carnaval. En las calles, en la televisión, en los medios de comunicación, en las redes sociales solo de habla de lo mismo. El sonido de los atabaques, panderetas de las marchiñas de carnaval están en todos los lugares. Existen muchas personas que disfrutan con el carnaval, sin embargo, otras escriben cartas. En este momento, hago parte del "bloque" que escribe cartas. En determinados momentos me siento como si formara parte de una fábula contada universalmente para niños de todo el mundo: "La cigarra y la hormiga". La que fuera originalmente escrita por Esopo y reescrita por de la Fontaine. En la mayor parte del Brasil las personas procuran aliviar sus penas y olvidar tristezas de su cotidianeidad o frenar los rumbos desastrosos del país impuesto por la actual política, a través del baile y la confraternización con sus personas amigas. Un homenaje a la vida, a pesar de las desigualdades sociales que se padecen en el día a día. Las cigarras, con sus bellas melodías, animan a las muchas hormigas que trabajan todo el año para llegar a esos días de carnaval. Actualmente, en todo el mundo existen grupos que promueven preconceptos. Todavía, no podemos olvidarnos de las personas que buscan, intensamente y en todo momento, romper con esos preconceptos y estereotipos.

En este edición de la revista, el lector y la lectora, tendrán la oportunidad de conocer algunas de esas personas que luchan en todo momento por romper con esas desigualdades sociales y buscan mejorar el día a día para todos. Son hormigas que se unen a las cigarras en una sola melodía. Estas personas son profesores, estudiantes, educadores sociales que trabajan y se divierten igualmente, buscando hacer lo mejor en todas las situaciones. En las fábulas tradicionales, las cigarras representan el placer en oposición al

e-ISSN:2172-7910

Doi: http://doi.org/10.25267/Hachetetepe.2020.i20.2

Universidad de Cádiz 
trabajo. Mientras tanto, gracias a los nuevos tiempos y las personas que están buscando romper con estos patrones, así como a través de la literatura infantil clásica que ha sido resucitada. En la actualidad, muchas historias infantiles rompen con la dualidad entre trabajar y el placer en la fábula de "La cigarra y la hormiga" y buscan la unión de las dos formas humanas, integrada y feliz.

Para organizar los artículos de la revista http, por ello, leyendo los textos, agradezco con cariño a todas las amigas y los amigos que aceptaron la invitación para escribir sus trabajos y cartas para la revista. Escribir cartas en tiempos modernos no es una tarea fácil. Zygmunt Bauman en su libro "44 cartas del mundo líquido moderno", escrito en 2011, presentaba sabiamente las angustias de una sociedad líquida, de inmediatismos, de incertezas, inconstancias y de movimientos constantes de muchas informaciones. Para el autor, la sociedad líquida trae muchos amigos a las redes sociales, pero mucha "soledad en medio de tanta multitud". Durante muchos años las cartas eran formas predominantes de comunicación y aproximación, incluso con la distancia con los familiares, amigos o colegas. El cartero era una persona muy esperada por las personas que aguardaban, ansiosamente, las cartas. Y la producción de las cartas también envolvían una especie de ritual. Algunas eran escritas con colores y bolígrafos especiales, incluso introduciendo olores y sabores. Igualmente, existen papeles de cartas especiales para la escritura más amorosa.

En esta sociedad actual, escribir cartas es un acto de resistencia y de amor. Escribir cartas envuelve un encuentro de las personas consigo mismas, con sus historias, subjetividades y pensamientos, además de requerir un tiempo para pensar sobre lo que se va a escribir, reflexionar sobre lo que es importante para sí y para el otro, con quien se desea comunicar. No es un acto simple, en tiempos en que confluyen diferentes formas de comunicación intervienen, asiduamente, algunas formas integradas y otras en disputa.

En esta revista, usted tendrá la oportunidad de conocer historias de personas que hacen "historia" en diferentes lugares del mundo. Sea con un artículo con las narrativas de profesores, contadores de historias y músicos de Paraná y de Bahía (Brasil) que se unirán para traducir el campo de estas artes a través de su imaginario presente en las cartas. O bien, contaremos con un artículo de una profesora de portugués de una escuela pública en el interior de Minas Gerais (Brasil). Conocí a esta mujer gracias al Canal Futura, un programa educativo de la televisión brasileña. En este programa fueron presentados los proyectos premiados de esta profesora como "Educadora Nota 10". Ella realizó un trabajo con adolescentes en la escuela vinculado a la escritura de cartas dirigidas al escritor brasileño, Guimarães Rosa (1908-1967), considerado uno de los mayores escritores de este país en el siglo XX. Estamos ante un clásico de la literatura que escribió mucho sobre el Sertão (zona seca del interior de Brasil) y su cultura popular. No obstante, a tenor de su estilo rebuscado, fueron pocas las personas que lograron comprenderlo. La profesora, sin embargo, incentivó y estimuló a su alumnado a que leyera su obra y, con ello, sus cartas, realizando vídeos sobre sus trabajos. Su propuesta de trabajo me encantó. Por ello, entré en contacto con ella a través de un mensaje escrito por las redes sociales y, en estos nuevos tiempos líquidos, mediados por los medios y llevadas por la fascinación por las cartas, nos tornamos amigas.

La presente revista también cuenta con un artículo de la Universidad Estadual de Ponta Grossa -UEPG- en Paraná, en unión con una profesora de la Universidad Federal de Juiz de Fora de Minas Gerais (Brasil) que describen y analizan las contribuiciones de la profesora e investigadora Mariazinha Fusari de la Universidad de São Paulo, que vivió

e-ISSN:2172-7910

Doi: http://doi.org/10.25267/Hachetetepe.2020.i20.2

Universidad de Cádiz 
poco tiempo entre nosotros; ahora bien, desarrollo un trabajo expresivo sobre alfabetización mediática en Brasil con sus estudios sobre medios, infancia y formación del profesorado.

En la perspectiva de discutir las cuestiones de los preconceptos raciales en las escuelas y en la sociedad tenemos dos artículos producidos por investigadores de la Universidad Estadual de Maringá y de la Universidad Federal Tecnológica de Paraná (Brasil), que abordan las narrativas escritas en cartas de acciones raciales sufridas por profesores negros y sus estrategias por enfrentar esta cuestión. Otro artículo presenta la dura realidad de una inmigrante haitiana y sus dificultades en Brasil.

En otro artículo se discute la formación del profesorado de Universidad de Rio Grande do Sul (Brasil) que presenta las contribuciones en cuanto estudio y proceso en que se desenvuelven con los niños de educación infantil, a través de los registros de cartas producidos por académicas de pedagogía sobre sus prácticas en estas escuelas.

Igualmente, tenemos un bloque de artículos de educadores sociales que desafiados y seducidos por la escritura de cartas, aceptan el desafío, intercambian ideas, sentimientos y reflexiones sobre las diferentes perspectivas de educadores sociales en Brasil, en los estados de Paraná y Espíritu Santo (Brasil). Junto a educadores de Uruguay, de Argentina $\mathrm{y}$, también, atravesando el océano, contando con la participación de Portugal. Estas personas trajeron relatos de estudiantes, mujeres educadoras y hombres educadores sociales que se corresponden y narran sus dificultades de reconocimiento de estos trabajos, de regularización de la profesión, así como las luchas diarias para un mundo mejor. Son cartas y textos que tocan el alma.

Deseamos que le guste nuestro trabajo y nuestras cartas.

Abrazos fraternos

Brasil, 24 de febrero de 2020. 